First Peoples Child \& Family Review

An Interdisciplinary Journal Honouring the Voices, Perspectives, and Knowledges of

First Peoples through Research, Critical Analyses, Stories, Standpoints and Media

Reviews

\title{
Towards Transformational Research for and with Indigenous Communities: The New British Columbia Indigenous Child Welfare Research Network
}

\section{Sandrina de Finney, Jacquie Green and Leslie Brown}

Volume 4, Number 2, 2009

URI: https://id.erudit.org/iderudit/1069340ar

DOI: https://doi.org/10.7202/1069340ar

See table of contents

Publisher(s)

First Nations Child and Family Caring Society of Canada

ISSN

1708-489X (print)

2293-6610 (digital)

Explore this journal

Cite this document

de Finney, S., Green, J. \& Brown, L. (2009). Towards Transformational Research for and with Indigenous Communities: The New British Columbia Indigenous Child Welfare Research Network. First Peoples Child \& Family Review, 4(2),

161-164. https://doi.org/10.7202/1069340ar

\section{Article abstract}

This article documents the development of the newly launched Indigenous Child Welfare Research Network in British Columbia. This Network is a provincial association of researchers, service providers, community members and policy makers with an interest in using Indigenous research in the transformation of child and family services. Rooted in a vision for healing and the inclusion of diverse voices, Network Initiatives seek to reclaim Indigenous ways of knowing and doing and reposition them at the core of child and family wellness initiatives. The Network provides a space for critical dialogue about Indigenous research, as well as opportunities for researched-related training, knowledge transmission and resource sharing.
Copyright (c) Sandrina de Finney, Jacquie Green, Leslie Brown, 2009
This document is protected by copyright law. Use of the services of Érudit (including reproduction) is subject to its terms and conditions, which can be viewed online.

https://apropos.erudit.org/en/users/policy-on-use/ 


\title{
ITirst Peoples Child \& samily Review
}

An Interdisciplinary Journal Honoring the Voices, Perspectives and Knowledges of First

Peoples through Research, Critical Analyses, Stories, Standpoints and Media Reviews

\section{Towards Transformational Research for and with Indigenous Communities: The New British Columbia Indigenous Child Welfare Research Network}

\author{
Sandrina de Finney ${ }^{\mathrm{a}}$, Jacquie Green ${ }^{\mathrm{b}}$ and Leslie Brown ${ }^{\mathrm{c}}$
}

${ }^{a}$ BA, Ph.D., Assistant Professor, School of Child and Youth Care, University of Victoria, Victoria, British Columbia, Canada.

${ }^{\mathrm{b}}$ BSW, MPA, Associate Professor, Faculty of Social Work, University of Victoria, Victoria, British Columbia, Canada.

${ }^{c}$ Ph.D., Associate Professor, Faculty of Social Work, University of Victoria, Victoria, British Columbia, Canada.

\section{A Vision for Transformation}

I did not know there was Indigenous ways of doing research. I am delighted to learn how to do research "in a good way." This is an excellent opportunity to create dialogue and network, share knowledge, and make research simple and accessible to our communities (Network research training participant).

How would child, family and community wellness be enhanced if Indigenous knowledge and values were integrated into every aspect of child and family services? How could Indigenous research play a role in this transformation? How would the growing rates of Indigenous children in care be impacted if Indigenous communities controlled the research that drives child welfare policy and practice? Given the horrific history of 'child welfare 'and 'research' with Indigenous communities, are these terms even appropriate to use with Indigenous families? How might research be conducted and applied more respectfully in and by our diverse communities?

Like many across Canada, policy makers, service providers and community members in British Columbia have been pursuing a vision for the transformation of the child welfare system and its concomitant practice

Questions or correspondence concerning this article may be addressed to:

sdefinn@uvic.ca

\begin{abstract}
This article documents the development of the newly launched Indigenous Child Welfare Research Network in British Columbia. This Network is a provincial association of researchers, service providers, community members and policy makers with an interest in using Indigenous research in the transformation of child and family services. Rooted in a vision for healing and the inclusion of diverse voices, Network initiatives seek to reclaim Indigenous ways of knowing and doing and reposition them at the core of child and family wellness initiatives. The Network provides a space for critical dialogue about Indigenous research, as well as opportunities for research-related training, knowledge transmission and resource sharing.
\end{abstract}

approaches that have not shown to be in the best interest of Indigenous communities. The efforts to remodel the child welfare system are evidenced by the growing number of Indigenous controlled child welfare agencies and by government and community attempts to restructure systems of authority and reviews of practice standards. While some attention has been given to rethinking policy and service development to make it more relevant to Indigenous peoples, research remains an under-utilized resource for effecting change in the area of child welfare. The dearth of Indigenous-driven research is in part underpinned by the contested history of research in Indigenous communities. Historically, Indigenous ways of caring for children and families have been dismissed as invalid, while too often Euro-Western 'scientific' research has been used to silence or appropriate Indigenous knowledges, and to justify harmful policies and practices. Despite growing efforts to Indigenize child and family services, much of the current research that underlies policy and evidence-based practice remains Euro-Western in its subject matter and methodological orientation.

The newly formed Indigenous Child Welfare Research Network in British Columbia responds to an 
urgent need for Indigenous research that is grounded in the voices of Indigenous children, youth, families and communities. We feel strongly that Indigenous control over research agendas, designs and applications would ensure a more foundational reflection of Indigenous voices in child and family policies and practice standards. Through the Network, we hope to contest the damaging legacy of child welfare research by centering research models that are more congruent with Indigenous worldviews.

\section{Our History}

In 2007, the Faculty of Human and Social Development at the University of Victoria identified the need for a provincial research strategy to support Indigenous child welfare policy and practice in British Columbia. To that end, in February of 2008, the Faculty called together key players from throughout the province to attend a forum to discuss a vision for Indigenous child welfare research. Out of this forum came the idea to establish a provincial Indigenous Child Welfare Research Network that would include Indigenous academics, community members, community organizations, Elders, young people, and those who hold a vested interest in our children.

The outcome of the one-day forum was a sense of collaboration and a growing momentum to draw on research to benefit Indigenous child, family and community wellness. Forum discussions stressed that past and current practices were not meeting the needs of Indigenous families and their communities. Participants spoke about the potential of a research network to re-claim Indigenous family and community knowledges in support of healing and wellness. One clear message coming out of the forum was that the time has come for communities and agencies to adapt research methods to meet their own needs. One forum participant emphasized the importance of recentering Indigenous ways of knowing as integral to a contemporary agenda for Indigenous research: "I think that Aboriginal research (i.e. historical data, traditional knowledge, traditional methodologies, full inclusion of diverse values and ethics1) has been a long time coming." Participants felt strongly that Indigenous knowledges and methodologies in their diverse forms would be relevant to both historical and contemporary issues facing Indigenous communities.

\footnotetext{
1 Network members have identified Aboriginal research methodologies and analysis as grounded in storytelling about topics such as child rearing, family values, knowledge of land and community, ceremony, and rites of passage.
}

The forum also reconfirmed the importance of being inclusive of all Indigenous Peoples 2 and particularly those of British Columbia, whose languages and cultural teachings are among the most diverse in Canada. Forum participants emphasized the need for research that speaks to differences between northern, southern, rural and urban realities. Many Elders reminded us that Network initiatives should honor different contexts but also promote collaboration between regions and sectors. Effective knowledge dissemination would enable communities and agencies across regions to share not only struggles, but also successful models of research.

Finally, forum participants stressed the importance of working across generations in order to achieve effective cycles of change. It was pointed out that community members, including Elders and youth, must be involved as full and equal partners in creating and benefiting from research. Many echoed the need for a renewed focus on child and youth engagement. One participant commented that "when there are publications about Indigenous children, Indigenous children should be able to read and understand the publication." This vision has remained at the core of our efforts to develop the Network. As expressed by one service provider, "it is very good to see that the hard work of our parents and grandparents is coming to fruition through the younger generation."

\section{Launching the Indigenous Child Welfare Research Network}

Following on the success of our first provincial forum, the Indigenous Child Welfare Research Network was officially launched on February 13, 2009. The BC Ministry of Children and Family Development granted start-up funds in order to grow the Network, develop Indigenous child welfare research training, and host a provincial conference in October 2009. We have established a governance system that includes a province-wide, inter-disciplinary community advisory committee with members of diverse backgrounds, ages and affiliations. Interested forum participants volunteered for the advisory committee and have taken on the responsibility of developing a research strategy that is reflective of diverse voices and realities across $\mathrm{BC}$. The long-term vision of the Network is to create a provincial research institute that will offer training and resources, support innovative Indigenous research, and facilitate connections between researchers, communities and organizations.

2 The Network strives to be inclusive of diverse Indigenous experiences. Our use of the term Indigenous includes Aboriginal, First Nations, Metis, Inuit, and other Indigenous Peoples worldwide. 
Our new website (www.uvic.ca/icwr) provides updated information on Network activities, a clearinghouse of research resources, research training information, and opportunities for dialogue and exchange. Network initiatives also include a newsletter, research projects, translation of research into accessible language, community consultations, and student mentorship. The Network also hosted a child welfare conference in Victoria on October 6 -7, 2009, which showcased the work of communities, organizations and researchers and supported collective dialogue for a way forward for the Network.

\section{Indigenous Research Training}

Among our many initiatives, we have developed a research training package that includes a two day training workshop and toolkit.3 The toolkit contains literature and multi-media resources (the majority from Indigenous sources) for the conduct of Indigenous research. These resources document various forms of Indigenous research such as traditional storytelling, community-based and action research, and Indigenous evaluation models. The toolkit is complemented by our regional training workshop, a two day interactive session that brings together local knowledge with research examples from diverse Indigenous communities. In order to reflect the realities of diverse Indigenous communities across $\mathrm{BC}$, each community training session is developed and delivered in collaboration with local partners, including Elders, youth, service providers and researchers. Training participants are invited to share resources, skills and strategies that address their specific community research needs. Contextualizing our research training to different regions avoids the top-down approach often espoused by university research.

The Network training package reinforces several key messages related to Indigenous research. First, it is critical that as community researchers and trainers we remain accountable to the communities we work with. Our initiatives are developed in close consultation with local Elders and leaders to ensure that we follow proper protocols when honoring local territories, conducting sessions, sharing stories, and thanking respected teachers and storytellers with appropriate gifts and words. In this way, we model reciprocity and ethical protocols for the respectful conduct of research.

Another important goal of our training is to demystify the very notion of research. As emphasized by a training participant, making research transparent and more accessible to Indigenous communities contests the

3 The training agenda and parts of the toolkit are available on our website to ensure that communities can develop and implement their own research goals. assumption that research belongs only to elites: "This [research training] challenged my belief that research can only be done by experts. It gives hope that Indigenous research can create meaningful, nurturing relationships and also create change and transformation for Indigenous people."

Finally is our assertion that Indigenous communities have always undertaken research. Indigenous research cannot be extricated from teachings that are deeply intertwined with every day life. We have heard from community after community that their research approaches are rooted in a process of storytelling, community consultation, collaborative analysis and evaluation, all guided by traditional protocols, ethics, and relationships. Many participants in our regional training sessions have shared cultural stories related to drumming, canoeing, basket weaving, child rearing and family governance, which provide important guidelines for conducting research. One training participant observed that the training reaffirmed the value of Indigenous teachings as an important form of research: "The training made it easy to realize that the basis of our lives is a journey of research and learning. So new, yet such an old methodology that has been steeped into our history for millennium past and a millennium to come."

\section{The Complex Work of Re-claiming}

Clearly, Indigenous methods have different but equally valid standards for ensuring relevance and accountability to community protocols and ethical guidelines. Our approach contests the prevalence of 'evidence-based practice' which imposes external research findings onto communities, instead honoring 'community-based evidence'. The documentation of community-based evidence is a much more holistic process that is guided by oral traditions and accountability to community governance structures, whereby Indigenous communities have full control in determining research goals, approaches and outcomes.

But the use of research as a transformational tool is certainly not straightforward. Our focus on community teachings as a basis for a new Indigenous agenda highlights the contradictions inherent in a process of re-claiming research. Our efforts to re-tell research stories involve re-thinking extremely burdened terms like 'research', 'methodology', 'evidence' and 'child welfare'. This 're-storying' responds to community requests for a new way of understanding and using research to meet multiple needs, both traditional and contemporary. At the same time, we are also confronted with the loaded history and limitations of research-related terminology, the need to return to ancient community concepts that are more deeply contextualized, and the importance of continuously 
evaluating our assumptions and language. Our work with the Network does not by any means resolve these longstanding tensions, but it is an important step forward. We hope to open a relational and conceptual space for critical but productive dialogue about Indigenous research that does not minimize these complexities.

We are also cognizant that Indigenous leaders, practitioners and governments must be able to effectively use our research as they work to improve the lives of families.

The paucity of Indigenous research has meant that they have had to rely on mainstream mentorship for direction. Our Network underscores that Indigenous research has much to contribute to partnership building and to collaboration with other sectors. One of our training participants commented that "much of this model can be implemented or integrated into any policy in our agencies. This training must be shared with mainstream society." A key component of building Indigenous research capacity is to translate community-based Indigenous methodologies into models for advocacy that can inform funders, government and other organizations in their development of good practices for our communities and families. Part of the ongoing work of the Network will be to build the credibility of Indigenous research and its potential for informing local community policy and practice with families. These are issues we hope to explore further in our work within the Network and in future articles.

\section{Join the Network!}

As it grows, the Network is becoming a gathering place for celebrating the positive programs espoused by Indigenous communities and organizations. The Indigenous Child Welfare Research Network supports a common vision for change, while seeking to remain inclusive of diverse voices. We invite everyone with an interest in supporting Indigenous children, families and communities to join our budding Network by visiting www.uvic.ca/icwr. Although the Network is BC-based, membership is open to anyone who wants to join.

This is a new beginning to a long and important journey, for the future of our children and their children's children (Network member). 